\title{
Photogrammetric Measurements of CEV Airbag Landing Attenuation Systems
}

\author{
Danny A. Barrows*, Alpheus W. Burner ${ }^{\dagger}$, Felecia C. Berry ${ }^{\ddagger}$, Harriett R. Dismond ${ }^{\S}$, and Kenneth H. Cate ${ }^{\S}$ \\ NASA Langley Research Center, Hampton, Virginia 23681
}

\begin{abstract}
High-speed photogrammetric measurements are being used to assess the impact dynamics of the Orion Crew Exploration Vehicle (CEV) for ground landing contingency upon return to earth. Test articles representative of the Orion capsule are dropped at the NASA Langley Landing and Impact Research (LandIR) Facility onto a sand / clay mixture representative of a dry lakebed from elevations as high as 62 feet (18.9 meters). Two different types of test articles have been evaluated: (1) half-scale metal shell models utilized to establish baseline impact dynamics and soil characterization, and (2) geometric full-scale drop models with shock-absorbing airbags which are being evaluated for their ability to cushion the impact of the Orion CEV with the earth's surface. This paper describes the application of the photogrammetric measurement technique and provides drop model trajectory and impact data that indicate the performance of the photogrammetric measurement system.
\end{abstract}

\section{INTRODUCTION}

NASA is developing the Orion Crew Exploration Vehicle as a replacement for the Space Shuttle for transporting astronauts to the International Space Station and other rendezvous modules placed in low earth orbit. ${ }^{1,2}$ The Orion capsule, figure 1 , will be the vehicle used for Earth reentry upon returning from missions to the moon and Mars. Two landing scenarios are being considered: (1) a water landing as was done for the Apollo series spacecraft, and (2) a landing on dry land. Dry land landings will require new shockabsorbing attenuation systems to dampen the impact to the Orion capsule and astronauts within. Deployable airbags are one landing attenuation system concept being studied, figure 2 . The deflated airbags would be stowed underneath the ablative heat shield and deployed, along with recovery parachutes, after the heat shield is jettisoned at an altitude of approximately 1000 $\mathrm{ft}$ (305 m). Airbag inflation will occur within the first 15 seconds of a 40 second descent, before a dry land

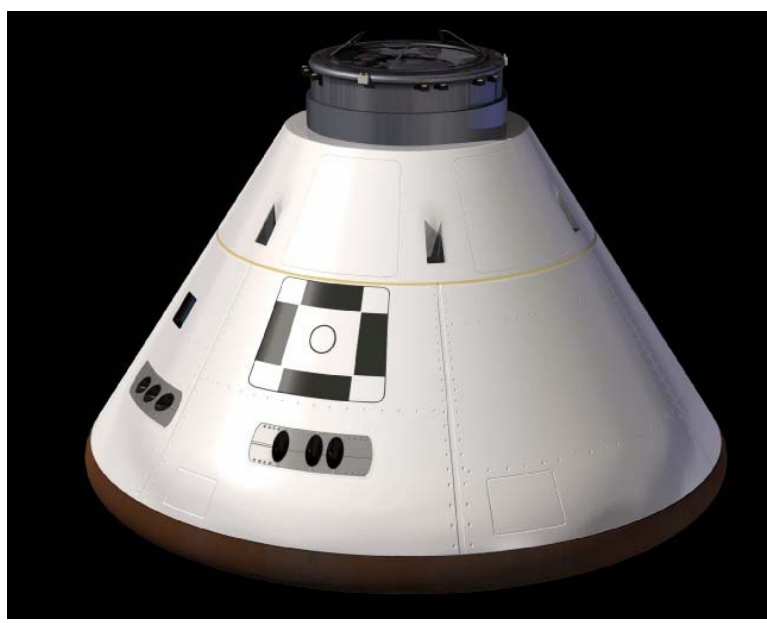

Figure 1: Artist's rendition of the Orion Crew Exploration Vehicle. touchdown is made at a vertical velocity of $25 \mathrm{ft} / \mathrm{s}(7.6 \mathrm{~m} / \mathrm{s})$.

\footnotetext{
* Aerospace Engr, Advanced Sensing and Optical Measurement Branch, M/S 493, Senior Member AIAA

† Senior Engineer, ROME Jacobs Sverdrup, M/S 267, Associate Fellow AIAA

‡ Electronics Engineer, Advanced Sensing and Optical Measurement Branch, M/S 493

${ }^{\S}$ Engineering Technician, Advanced Sensing and Optical Measurement Branch, M/S 493
} 


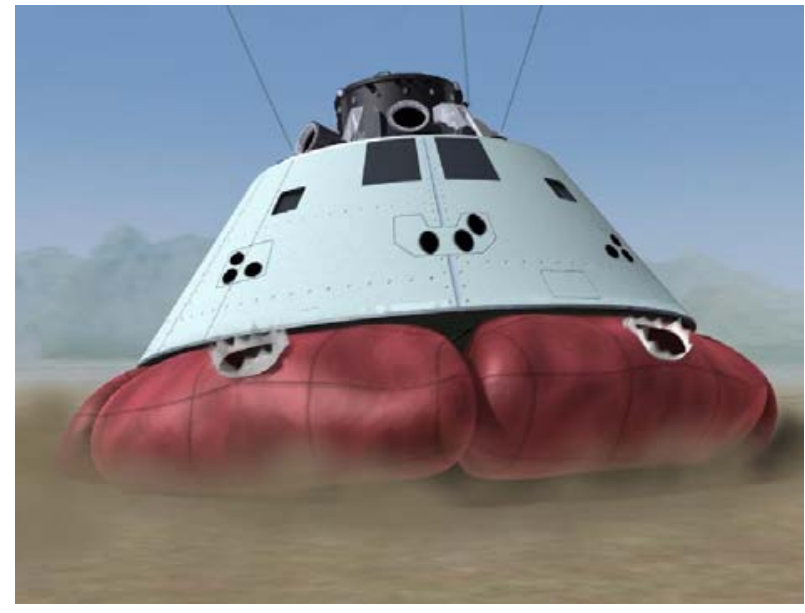

Figure 2: Artist's rendition of Orion with airbag landing attenuation system.

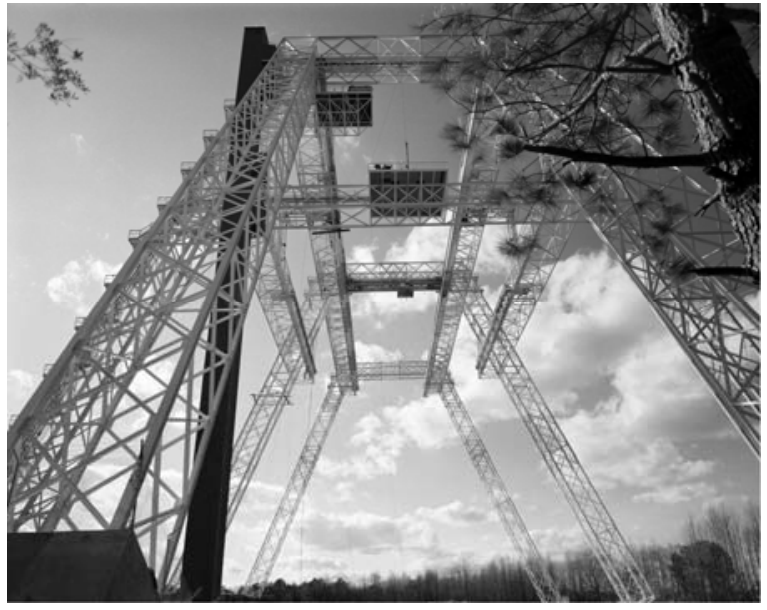

Figure 3: LandIR Facility at NASA Langley Research Center, Hampton, Virginia.

Experimental tests are underway at the NASA Langley Landing and Impact Research (LandIR) Facility, Hampton, Virginia, to evaluate the efficacy of different airbag designs and their ability to cushion the impact of the Orion capsule upon ground impact. These tests are conducted using drop models having a shape representative of an Orion capsule. The models are lifted to specified heights - some as high as $35 \mathrm{ft}(10.7 \mathrm{~m})$ - then dropped onto a sand / clay mixture that simulates possible Orion landing sites such as dry lakebeds in the California and Nevada deserts. High-speed, high-resolution video cameras record the drop and impact sequences. Photogrammetric measurement techniques are then applied to the high-speed video sequences to extract drop model trajectory and impact dynamics data. The photogrammetric data, along with data produced by other instrumentation onboard the drop models, are utilized to validate and enhance computational models that analytically predict the behavior of the test articles and airbags.

This paper describes the application of the photogrammetric measurement technique and provides representative drop model trajectory and impact data that indicate the performance of the photogrammetric measurement system. Photogrammetric data were obtained for 41 drops during the initial 2006 - 2007 test campaign; thus the data shown in this paper represents but a small fraction of the overall data set. The quality of the photogrammetric data presented is typical of that achieved for each drop test performed to date and is indicative of the type of performance that can be attained for future tests. Testing will continue throughout 2008 using full-scale drop models that are accurately scaled in size, shape, and weight to simulate the actual Orion capsule. These models will be utilized to evaluate second generation airbag designs.

\section{EXPERIMENTAL HARDWARE}

\section{A. LANDING IMPACT RESEARCH (LandIR) FACILITY}

Figure 3 shows a photograph of the NASA Langley LandIR Facility. The facility consists of a $240 \mathrm{ft}$ (73 m) high steel truss gantry structure. Crosswalks connect three A-frames that support a moveable bridge, used to raise and drop test articles from designated drop heights. This facility has a historic past; the gantry structure was originally built in the 1960s and was used as a lunar landing research and training facility. ${ }^{3}$ This facility enabled Apollo astronauts to practice piloting a simulated lunar module during the last $150 \mathrm{ft}(45.7 \mathrm{~m})$ of descent onto the lunar surface. Some 40 years later, the facility is once again being utilized to support NASA space missions through ground impact testing of the Orion crew module. Steel cables suspended from the LandIR gantry are utilized to raise Orion drop models to pre-determined heights. The models are then dropped to the simulated dry lakebed surface below. Two different types of drop tests have been conducted for models with and without airbags: (1) straight vertical drops, and (2) pendulum-style swing drops. Vertical drops are performed using remotely activated release hooks that suspend the Orion drop models above the ground. Vertical drops up to heights of $16 \mathrm{ft}(4.9 \mathrm{~m})$ reaching impact velocities of $32 \mathrm{ft} / \mathrm{s}(9.8 \mathrm{~m} / \mathrm{s})$ have been performed to date. Pendulum-style swing tests, figure 4, are performed using a series of pyrotechnic devices that sever the Orion model support cables in a predetermined 


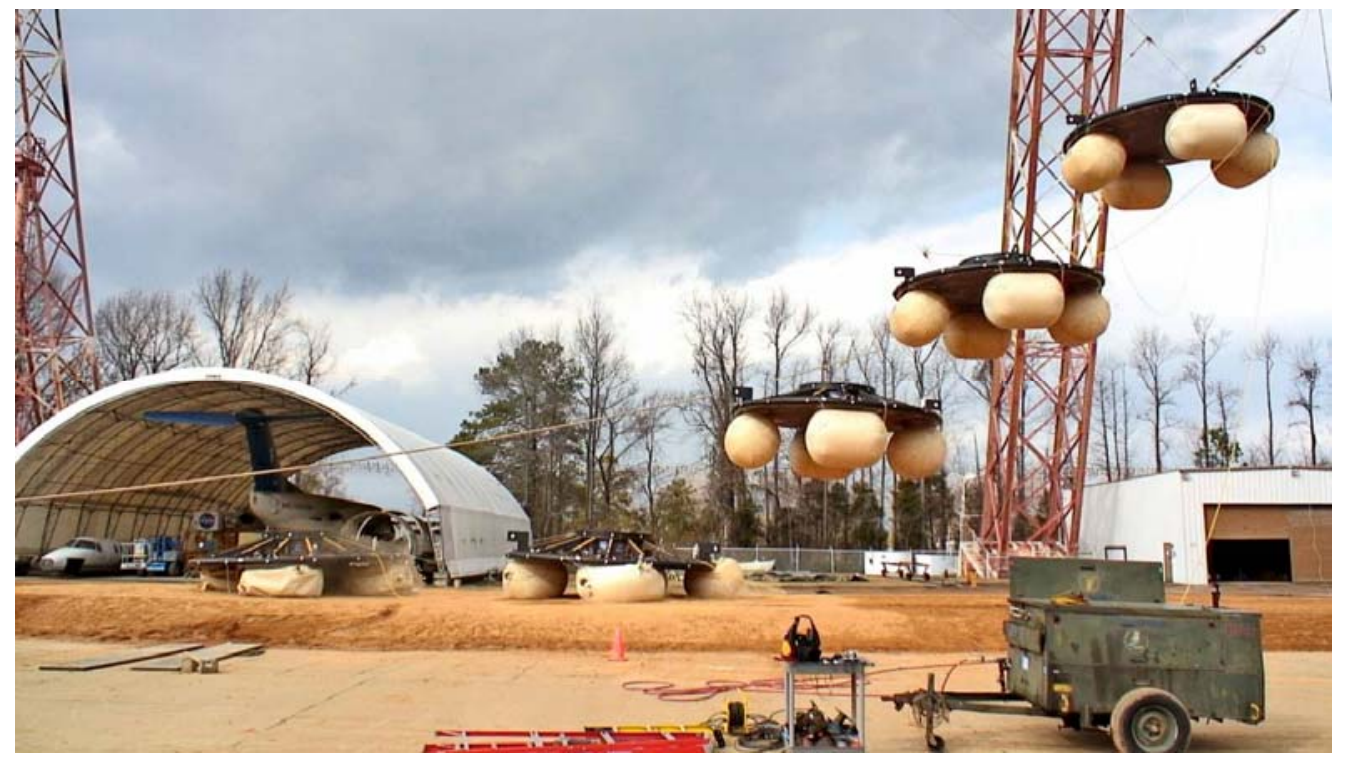

Figure 4: Time-lapse composite image of pendulum-style drop test of airbag model.

manner. The first pyrotechnic cutter initiates a swing by releasing the suspended Orion model, sending it in motion. A second set of pyrotechnic cutters sever the swing cables from the drop model within a few milliseconds of ground contact. This gives the model full freedom to continue through the remainder of the test without tether. Pendulumstyle drops have been conducted at starting heights of $62 \mathrm{ft}(18.9 \mathrm{~m})$, reaching impact velocities up to $25 \mathrm{ft} / \mathrm{s}$ (7.6 m) vertical and $58 \mathrm{ft} / \mathrm{s}(17.7 \mathrm{~m} / \mathrm{s})$ horizontal.

\section{B. ORION DROP TEST MODELS}

Two different types of drop models were utilized during the initial test campaign: (1) half-scale metal shell models utilized to establish baseline impact dynamics and soil characterization, and (2) geometric full-scale drop models with shock-absorbing airbags. Both types of models contained on-board instrumentation including accelerometers, inclinometers, angular rate sensors, pressure transducers, thermocouples, and tri-axial MEMS gyroscopes.

\section{B1. Half-scale metal shell models}

Figures 5 and 6 show the first- and second-generation half-scale metal shell models used during the initial test campaign. These models were fabricated from steel and did not have airbag landing attenuation systems. The metal shell models were primarily designed for model performance studies, soil impact characterization, and training of test personnel. The model shown in figure 6 replicates a half-scale version of the Orion capsule by its proportional shape, size (8 ft (2.4 m) diameter), and approximate weight of $4100 \mathrm{lbs}(1860 \mathrm{~kg})$. The white dots placed about the structural periphery of the models are targets used for photogrammetric measurements throughout the drop and impact events.

\section{B2. Airbag Testing model}

The drop model used for airbag testing is shown in figure 7. The airbag tests performed to date have used a simplified drop model to gain confidence when demonstrating a representative concept of overall airbag design. These initial tests have not been intended to provide accurate assessments of the landing impact of a full-scale Orion capsule - this will be the subject of future testing. The airbag drop model is a 3/8 in $(1 \mathrm{~cm})$ thick flat steel plate approximately $16.5 \mathrm{ft}(5 \mathrm{~m})$ in diameter. A $6.5 \mathrm{in}$. $(16.5 \mathrm{~cm})$ diameter steel tube wraps around the circumference of the drop model to prevent the airbags from being punctured. The airbag drop model is $2.5 \mathrm{ft}(76 \mathrm{~cm})$ tall without any airbags attached and weighs $6400 \mathrm{lbs}(2903 \mathrm{~kg})$, less than half the weight of the actual Orion crew module. Initial tests have utilized three and four airbags - about half the expected six airbags required for the actual Orion 


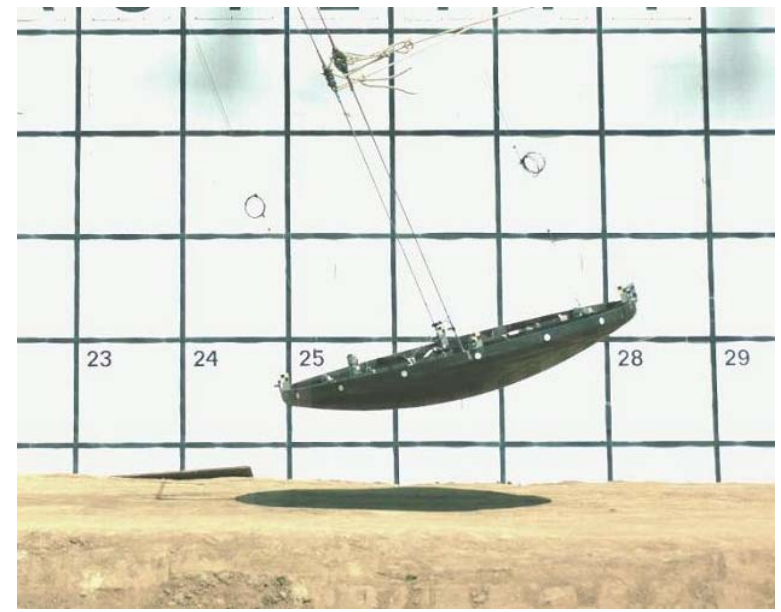

Figure 5: First generation metal shell drop model.

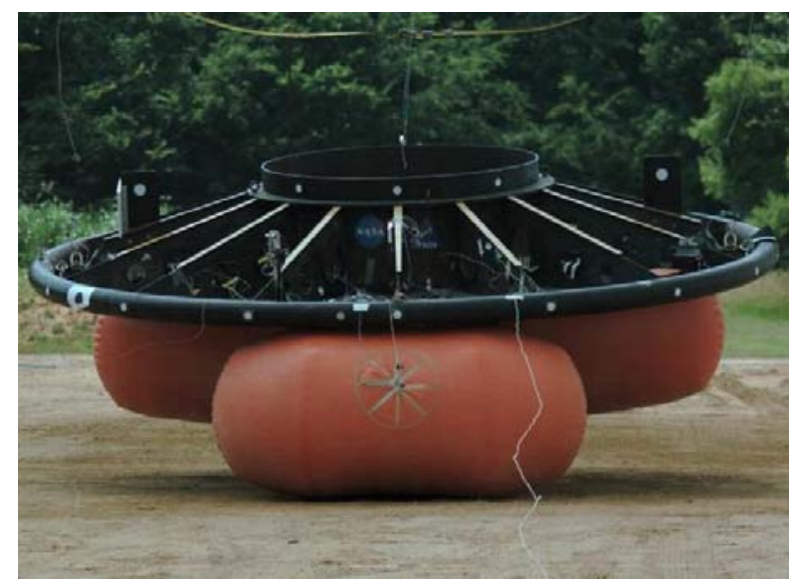

Figure 7: Airbag drop test model.

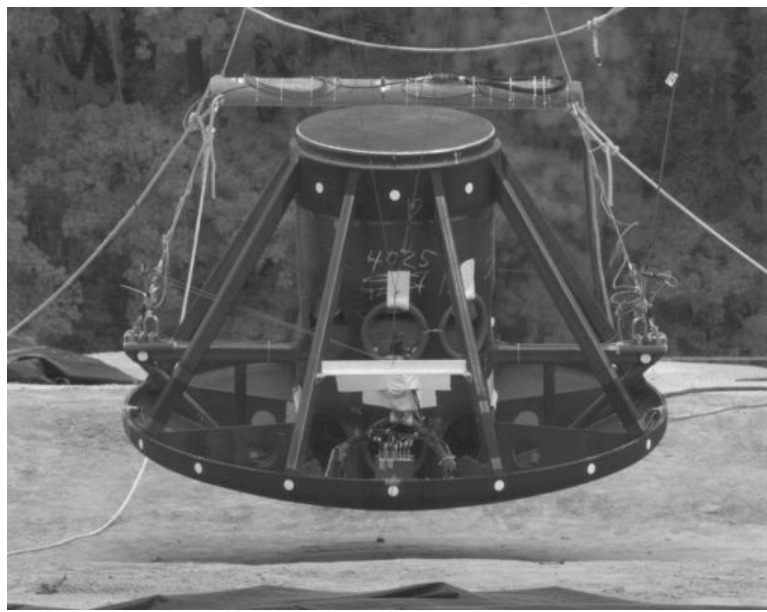

Figure 6: Second generation half-scale Orion metal shell drop model.

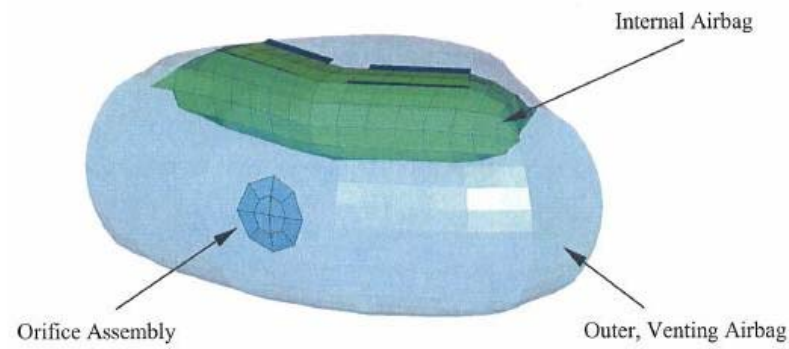

Figure 8: Landing attenuation airbag conceptual design.

crew module - attached to the underside of the drop model. The airbags are inflated prior to the drop with the model suspended a few feet above the ground. The model is then raised to its predetermined drop height after the bags have been fully inflated. As with the metal shell models, the white dot targets mounted on the airbag model structure are used for photogrammetric measurements throughout the drop and impact events.

Figure 8 shows the airbag conceptual design. ${ }^{4}$ Each airbag consists of permanently inflated bags inside of venting bags. The venting bags utilize customized orifices that release compressed gases upon impact, controlling gas flow rates to maximize efficiency. An optimal airbag system design would provide spring like landings with the airbags dissipating energy generated during impact and minimizing bounce. NASA has partnered with Irvin Aerospace, Inc. and ILC Dover for airbag development. Their independent designs both include controlled discharges of compressed air from within the airbags upon contact with the ground. This design principle allows the force of impact to be dampened quickly and the test article / crew module to settle without excessive bouncing.

A total of 20 airbag model drop tests (8 vertical, 12 pendulum) were conducted during the initial test campaign from December 2006 to June 2007. The impact velocities of the 8 vertical drops ranged from 10 to $32 \mathrm{ft} / \mathrm{s}$ ( 3 to 9.8 $\mathrm{m} / \mathrm{s}$ ). The horizontal velocities of the 12 pendulum drops ranged from 20 to $40 \mathrm{ft} / \mathrm{s}$ (6.1 to $12.2 \mathrm{~m} / \mathrm{s}$ ), with a corresponding vertical velocity of $25 \mathrm{ft} / \mathrm{s}(7.6 \mathrm{~m} / \mathrm{s})$ on impact. 


\section{HIGH SPEED VIDEO CAMERAS}

Five Vision Research, Inc. Phantom high-speed video cameras were utilized to record each drop test at a rate of 1000 frames per second. A combination of Phantom series 7 and series 9 cameras were used. Table 1 shows the relevant imaging characteristics of the series 7 and series 9 cameras. For testing to date, all cameras have been triggered manually from laptop computers that interface with the cameras. For future testing, all cameras will be temporally synchronized and simultaneously triggered to begin video acquisition. Three cameras are typically placed perpendicular to the pendulum drop swing plane to capture side views of the test article throughout the drop test. These cameras are designated as North / South cameras to denote the camera viewing directions. Two additional cameras positioned within the swing plane record video from the front (model swinging toward camera) and back (model swinging away from camera) perspectives. These in-plane cameras are designated as East / West cameras. Each camera was mounted on its own tripod and leveled in two directions with bubble levels. Video was recorded to volatile memory on-board each Phantom camera then downloaded to hard disk at the conclusion of each drop.

Table 1. Imaging Characteristics of Vision Research, Inc. Phantom Series Cameras

\begin{tabular}{|l|l|l|}
\hline & Phantom Series V7.0 & Phantom Series V9.1 \\
\hline Frame Rate (frames / second) & 1000 & 1000 \\
\hline Greyscale or Color & Greyscale & Color \\
\hline Resolution (width $\times$ height, pixels) & $800 \times 600$ & $1632 \times 1200$ \\
\hline Camera Lens; Focal Length (mm) & Nikon fixed fl; 60, 90, 105 & Nikon fixed fl; 35, 50, 60, 90, 105 \\
\hline Pixel Size (microns) & 22 & 11.5 \\
\hline Recording Capacity (GB) sec. & 6, Internal Memory; 6.0 & 6, Internal Memory; 3.2 \\
\hline
\end{tabular}




\section{PHOTOGRAMMETRIC ANALYSIS}

\section{A. Photogrammetric Analysis Methodology}

For the initial test campaign two-dimensional analyses of the drop model impact dynamics within the swing plane were sufficient for analytical model development and validation since temporal identification of primary impact dynamics features, such as initial impact, attitude change, first bounce, etc. was deemed to be more important than obtaining high accuracy spatial values of those events. The model trajectory and impact data required could therefore be obtained using views from individual high-speed video cameras placed perpendicular to the drop model swing plane.

The methods employed to extract drop model trajectory and impact data from the high-speed video sequences were based on the principles of single view close-range photogrammetry. ${ }^{5}$ By these principles, the photogrammetric collinearity equations reduce to a simple image-to-object plane magnification scaling if the drop model remains predominantly within the swing plane (minimal out-of-plane motion) and optical system distortions are assumed negligible. Both of these constraints were met throughout the initial test campaign. Observations of multiple drop events using the East / West cameras, which provided views within the swing plane, confirmed the drop models exhibited negligible out-of-plane motion during drop and impact events. Video system optical distortions were minimized through the use of relatively long fixed focal length 35-mm format lenses normally used for highquality film cameras. Perspective distortion was minimized by carefully aligning the cameras perpendicular to the swing plane.

Analysis of the high-speed video sequences obtained from each drop event was performed on a frame-by-frame basis in grayscale mode. For color video obtained using the Phantom 9 camera, processing was performed using only the blue channel from the red-green-blue (RGB) color triplet comprising each image since the blue channel was found to provide superior contrast. Custom MATLAB ${ }^{\mathrm{TM}}$ code was developed to perform the initial manual identification of each photogrammetry target and then to automatically track each target throughout the video sequence. Diffuse white dots on a black background were used as photogrammetric targets with typical target IDs shown in figure 9. The contrast afforded by these targets made automated frame-by-frame tracking reliable, although tracking of discrete targets was occasionally disrupted when the view of a target was obstructed by guide wires, tether ropes, or dust that was kicked up on impact. Progressing sequentially forward through the video frames, the position of each target within each video frame was determined to $\sim 0.1$-pixel accuracy by computing the grayscale-weighted target centroid location. If tracking of a specific target was lost due to ropes, dust, etc., an indicator flag was set within the software and no

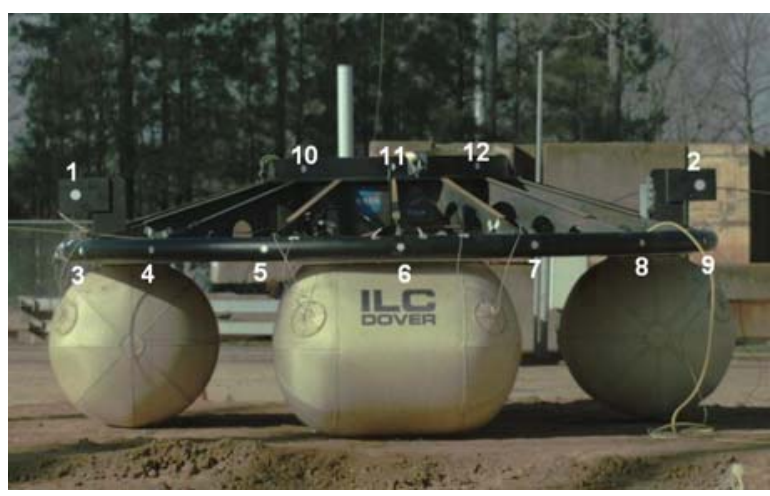

Figure 9: Photogrammetry targets on airbag drop model and typical target numbering convention.

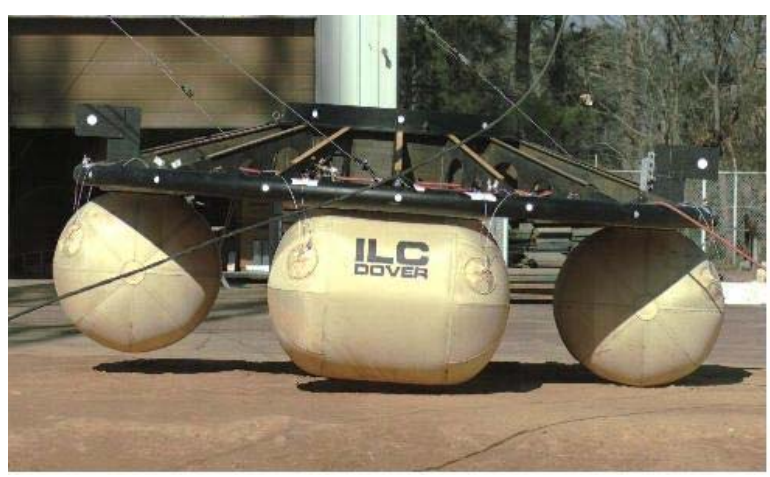

Figure 10: Single frame of high-speed (1 kHz) video showing ground impact of airbag drop model outfitted with ILC Dover airbags.

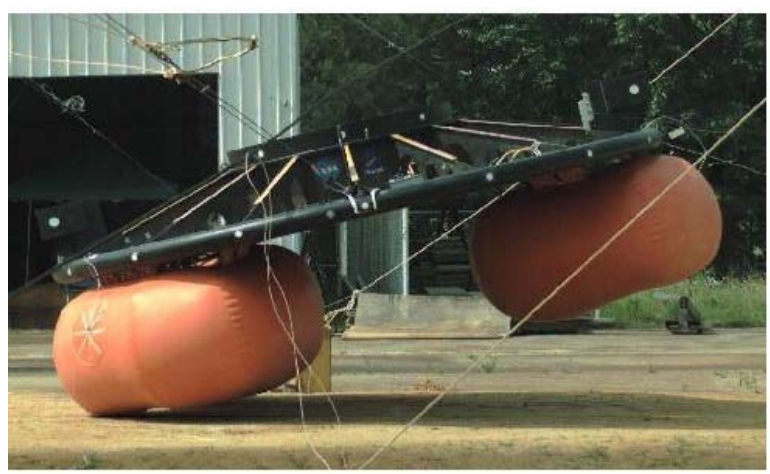

Figure 11: Single frame of high-speed $(1 \mathrm{kHz})$ video showing ground impact of airbag drop model outfitted with Irvin Aerospace airbags. 
further attempt was made to track that target during the forward processing sequence. At the conclusion of the forward processing sequence, the software would check these indicator flags to see if tracking had been lost for any target. If so, the processing software would automatically begin to reprocess the video in reverse order, tracking the positions of any targets whose tracking had been lost in the forward processing sequence. This method allowed for the recovery of a majority of target position data in the latter part of the video sequence that occurred after target tracking was lost due to obstructions from wires, ropes, and dust. The target centroid locations were then converted from image plane pixel units to object plane engineering units by multiplying by the image-to-object plane scaling factor. The target position data were also uniformly shifted in time to set time $\mathrm{T}=0$ at the point of impact of the test article with the ground. The time of impact could typically be determined to within \pm 2 milliseconds ( \pm 2 video frames) by visual inspection of the high-speed video sequences, for example as in the frames of figures 10 and 11 . Further analyses of the target position data were performed to determine the test article horizontal and vertical velocity and trajectory angles. Trajectory angles were computed using the relative positions of two targets that were far apart on the test article, typically the targets labeled 1 and 2 in figure 9. Computing angles using targets with a large separation distance provided improved measurement accuracy compared to angle measurements using closely spaced targets.

\section{B. Measurement Uncertainty Considerations}

A known target separation between a pair of reference targets is used to determine the scaling multiplier that converts image plane pixels to engineering units. The image scaling multiplier is determined from the video frame at the time of impact. The targets labeled 1 and 2 in figure 9 are the best choice for the reference targets since they are situated on the centerline cross-section of the vehicle and represent the outer most target pair. Linear scales are used to measure target separations to within an estimated \pm 0.2 inches $(0.5 \mathrm{~cm})$. (The error in the length measurement of the reference target spacing is larger than might be normally expected since there is no clear line-ofsight path from target-to-target due to blockage by model structural components.) The reference length used to determine the scaling multiplier will then have a measurement error of $0.1 \%$ for the typical target separation of 188 inches $(478 \mathrm{~cm})$. Figure 12 shows the apparent change in distance between a target pair measured photogrammetrically over time as the drop model moves across the image plane. Figure 12 is typical for both the vertical drops and the swing drops when excessive out of plane motion is not present. The 1-inch $(2.5 \mathrm{~cm})$ change in the data over a $1.5 \mathrm{sec}$ period of time represents an approximate $0.5 \%$ maximum change in apparent target pair separation. Since the 1-standard deviation centroiding repeatability is better than 0.1 pixel, a data scatter of 0.02 inch is expected based on the typical scaling multiplier. The local scatter of the data for figure 12 of 0.1 inch peakto-peak (corresponding to $\sim 4 \times$ standard deviation) is roughly consistent with this centroiding repeatability. When out-of-plane motion is negligible, the bias error for displacement is taken to be $0.5 \%$ with a corresponding precision of 0.04 inch (2-sigma). The corresponding bias error for velocity is also taken to be $0.5 \%$ when out-of-plane motion is negligible. The relatively large scatter in velocity measurements when computed frame-by-frame is lessened by computing a running mean over 20 frames $(0.02 \mathrm{sec})$. The local scatter representing the precision of the running mean of velocity measurements over 20 frames is then found to be about $0.04 \mathrm{fps}$ (2-sigma). Thus the bias and precision for velocity are taken to be $0.5 \%$ and 0.04 fps respectively. For both displacement and velocity the total estimated uncertainty is then taken to be \pm the sum of the bias and precision. 


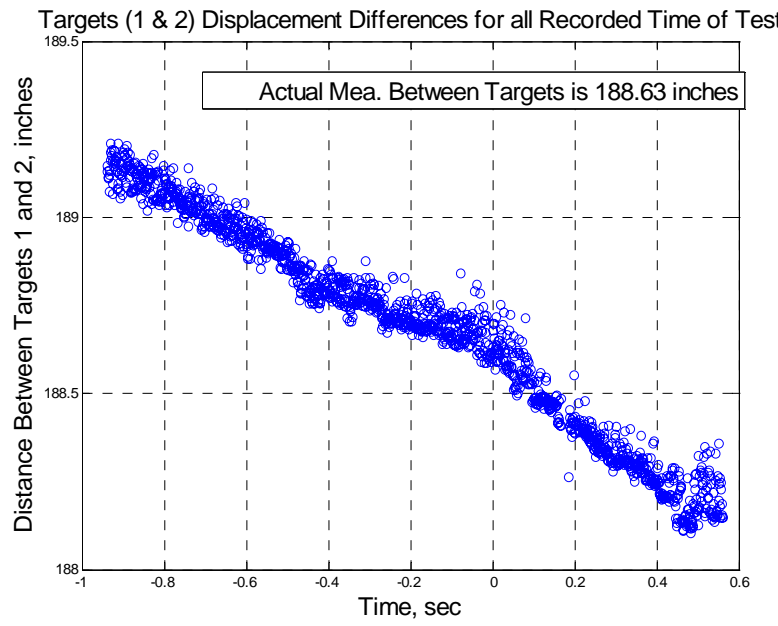

Figure 12: Typical comparison between photogrammetry and scaled measured target separation. Ground contact at $\mathbf{T}=\mathbf{0}$.

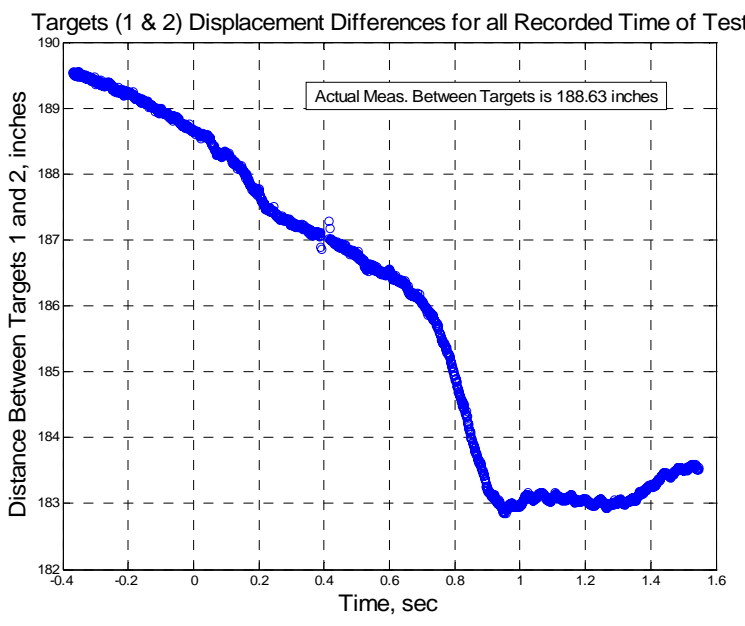

Figure 13: Extreme comparison between photogrammetry and scaled measured target separation. Ground contact at $\mathbf{T}=\mathbf{0}$.

The plot in figure 13 is a worst-case scenario for an out of plane motion of a CEV drop model. This test entails a pendulum style drop designed to have a $10^{\circ}$ yaw-angle that causes an immediate roll as the vehicle makes contact with the ground. In other words, when facing the model in the direction of the swing the left hand side of the model is $10^{\circ}$ lower than the right hand side. At impact the vehicle rolls about the LHS airbag which impacts first. With this rather large out-of-plane motion the photogrammetrically determined target pair spacing has an apparent change totaling about 6.5-inches over 2 seconds. Such a large change in apparent target pair spacing is a good indicator that the model is experiencing an out-of-plane roll and that the image-scaled data are suspect without further correction.

Unlike displacement and velocity, angularity measurements can be made using 2D image plane pixel data alone to calculate pitch and yaw angle changes. The error for angle measurements can be estimated from the error of determining centroids of the 2 targets making up a pair relative to their separation in pixels. For typical imagery where the target pair separation ranges from 275 to 850 pixels, the error would range from $0.03^{\circ}$ to $0.01^{\circ}$. A value of $0.06^{\circ}$ is taken as the estimated bias error to partially allow for uncompensated lens and perspective distortion. The 2-sigma precision of angle measurements is found from residuals of least squares fits to linear regions of the photogrammetrically determined angle data to be about $0.006^{\circ}$. Thus the bias and precision of angle measurements are taken to be $0.06^{\circ}$ and $0.006^{\circ}$ respectively. The total estimated uncertainty is then taken to be \pm the sum of the bias and precision.

\section{TYPICAL RESULTS}

The results presented here are typical of the quality of the photogrammetric measurements obtained but comprise only a small fraction of the data set acquired during the 2006-2007 initial test campaign. In all, photogrammetric analyses of high-speed image data were conducted for 41 soil characterization and land attenuation tests. Three data sets acquired during the 2006-2007 testing period are presented as representative data. The first, conducted in late 2006 on a half-scale vehicle without any airbag attenuation system (figure 14) was a scheduled 20 $\mathrm{ft} / \mathrm{s}(6.1 \mathrm{~m} / \mathrm{s})$ horizontal, $5 \mathrm{ft} / \mathrm{s}(1.5 \mathrm{~m} / \mathrm{s})$ vertical, and $15^{\circ}$ toe-in pitch angle test. The starting height was $8 \mathrm{ft}(2.4 \mathrm{~m})$ above a hard dry dirt surface. The average resultant velocity from the test at the time of impact was $20.45 \mathrm{ft} / \mathrm{s}(6.2$ $\mathrm{m} / \mathrm{s})$ (horizontal velocity $=19.75 \mathrm{ft} / \mathrm{s}(6.02 \mathrm{~m})$ and vertical velocity $=5.32 \mathrm{ft} / \mathrm{s}(1.62 \mathrm{~m}))$, with a toe-in pitch angle of $13.98^{\circ}$. The displacement plot in figure 15 illustrates the linear horizontal and vertical motion during the time of flight before impact. A small pitch angle change of $0.22^{\circ}$ at a rate of $0.82^{\circ} / \mathrm{sec}$ can be seen in figure 16 for the last 


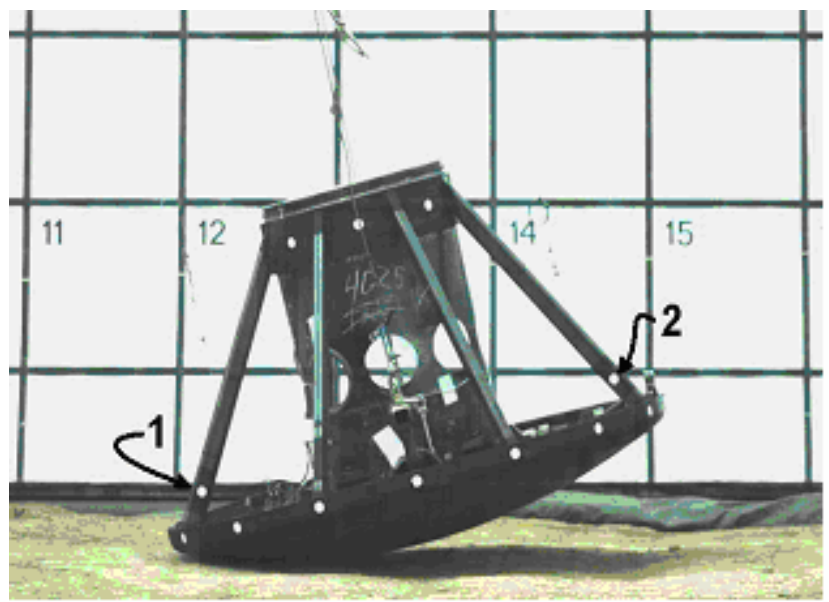

Figure 14: Second generation half-scale Orion metal shell drop model with two targets singled out.

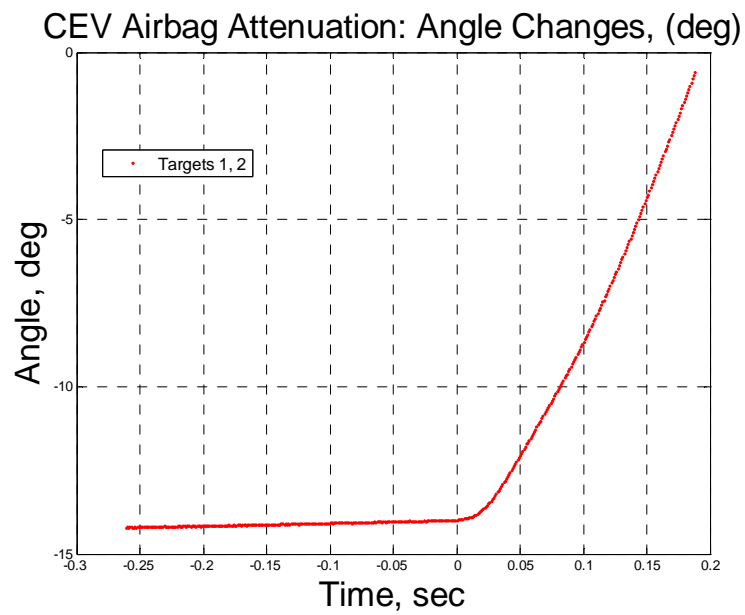

Figure 16: Second generation half-scale drop model pitch angle changes before and after touchdown at $\mathbf{T}=\mathbf{0}$.
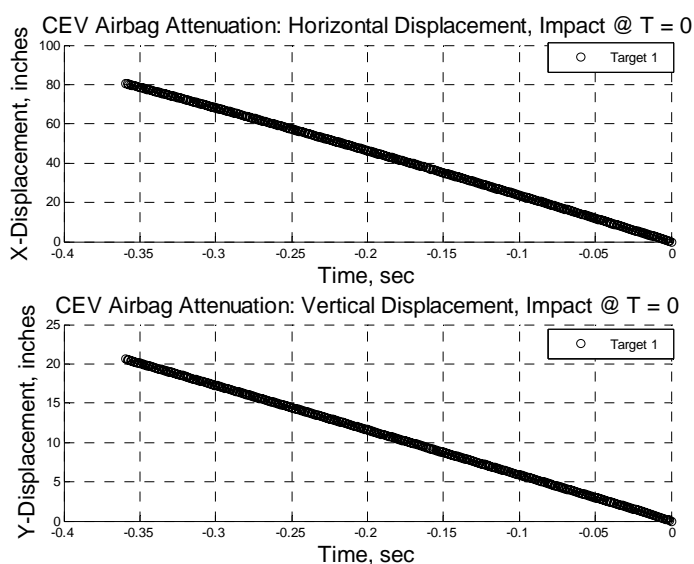

Figure 15: Second generation half-scale drop model displacement data to $\mathbf{T}=\mathbf{0}$.

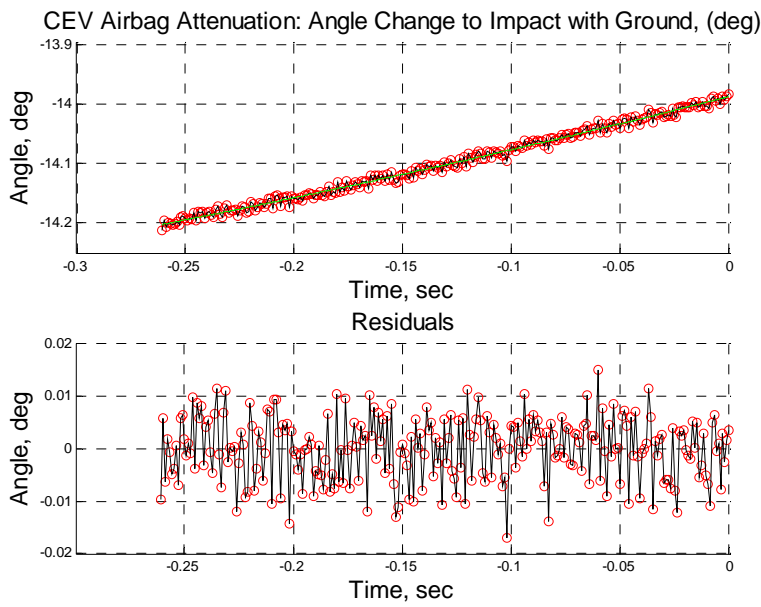

Figure 17: Second generation half-scale drop model pitch angle changes for last 0.25 (sec) before touchdown at $\mathrm{T}=\mathbf{0}$.

0.26 seconds of flight before ground contact is made. After ground contact the drop model pitches from toe to heel on the rounded underside (simulating the heat shield) causing a large increase in angle. Residuals of the linear least squares fit to the angle computation of about $\pm 0.01^{\circ}$ peak-to-peak are shown in figure 17 . Note the sudden spike in vertical velocity in figure 19 at $\mathrm{T}=0$ caused by the release of the swing cables prior to impact. The earlier than planned for release increased the vertical velocity for the drop. After touchdown the horizontal velocity of the model remains steady as it slows towards a stop, as seen in figure 18. The front of the model quickly falls to zero vertical velocity for an instant, as it pitches from heel to toe, as seen in figure 19. 


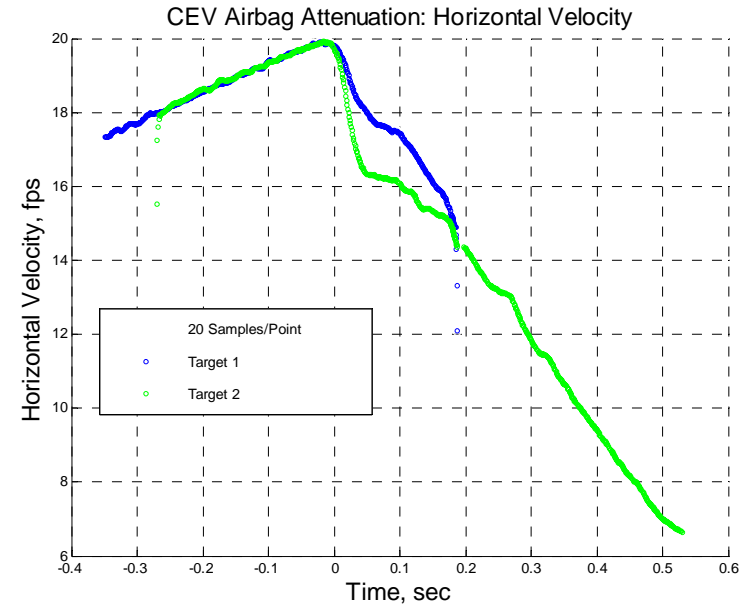

Figure 18: Second generation half-scale drop model horizontal velocity over time, before and after touchdown at

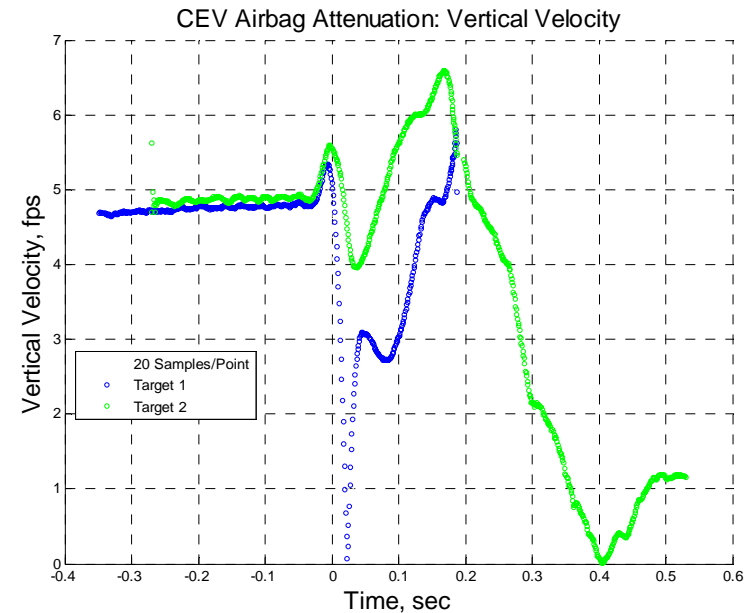

Figure 19: Second generation half-scale drop model vertical velocity over time, before and after touchdown at $\mathbf{T}=\mathbf{0}$.

The second test is a vertical-style drop with an airbag attenuation system attached to a new vehicle, discussed earlier in section II, B2 (Airbag Testing Model). The test plans for this model included $0.0 \mathrm{ft} / \mathrm{s} \mathrm{horizontal} \mathrm{and} 25 \mathrm{ft} / \mathrm{s}$ $(7.62 \mathrm{~m} / \mathrm{s})$ vertical, without induced pitch or yaw angles. The starting height was $10.5 \mathrm{ft}$ (3.2 m) above a spongy soft dirt surface. The average resultant velocity at the time of impact was $24.54 \mathrm{ft} / \mathrm{s}(7.48 \mathrm{~m} / \mathrm{s})$ (horizontal velocity = $0.39 \mathrm{ft} / \mathrm{s}(0.12 \mathrm{~m})$ and vertical velocity $=24.54 \mathrm{ft} / \mathrm{s}(7.48 \mathrm{~m}))$. The first recorded evidence of the yaw angle was $1.44^{\circ}$ at T-minus 0.591 sec. The displacement plots in figures 20 and 21 show the motion of the vehicle for almost the entire test. Figure 21 shows an expanded view of the vertical displacement starting at $\mathrm{T}=0$. A vertical oscillation of a few inches is observed as the vehicle oscillations dampen in 2.41 seconds. Figure 22 suggests the model had very little roll as it descended to the ground and bounced on the inner airbags to a stop. A small yaw angle present at the time of launch decreased at a rate of $0.63 \%$ sec as the vehicle descended, as shown in figure 23 . The peak velocity of $24.54 \mathrm{ft} / \mathrm{s}(7.48 \mathrm{~m} / \mathrm{s})$ at $\mathrm{T}=0$ is within $98 \%$ of the $25 \mathrm{ft} / \mathrm{s}(7.62 \mathrm{~m} / \mathrm{s})$ test goal. The vehicle velocity reaches zero within $\mathrm{T}=0.165 \mathrm{sec}$, after which it then bounces many times to a rest on the inner airbags sometime after $\mathrm{T}=2.5 \mathrm{sec}$, as shown in figure 25 .

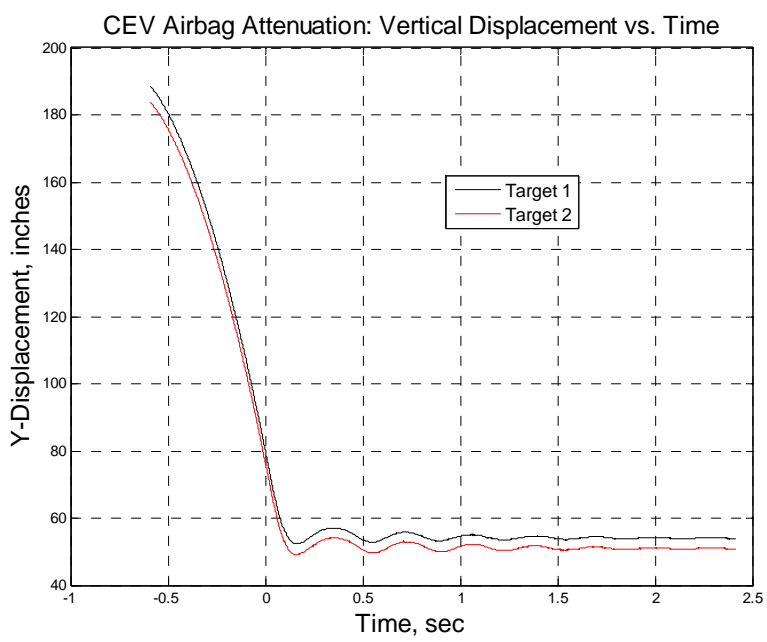

Figure 20: Airbag attenuation vertical-drop model displacement over time, before and after touchdown at $\mathbf{T}=\mathbf{0}$.

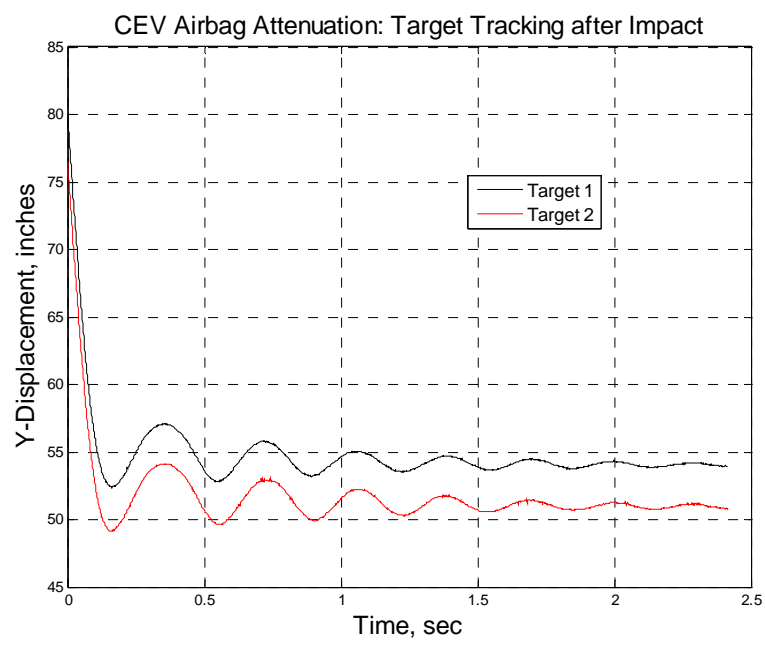

Figure 21: Airbag attenuation vertical-drop model displacement over time, after touchdown at $\mathbf{T}=\mathbf{0}$. 


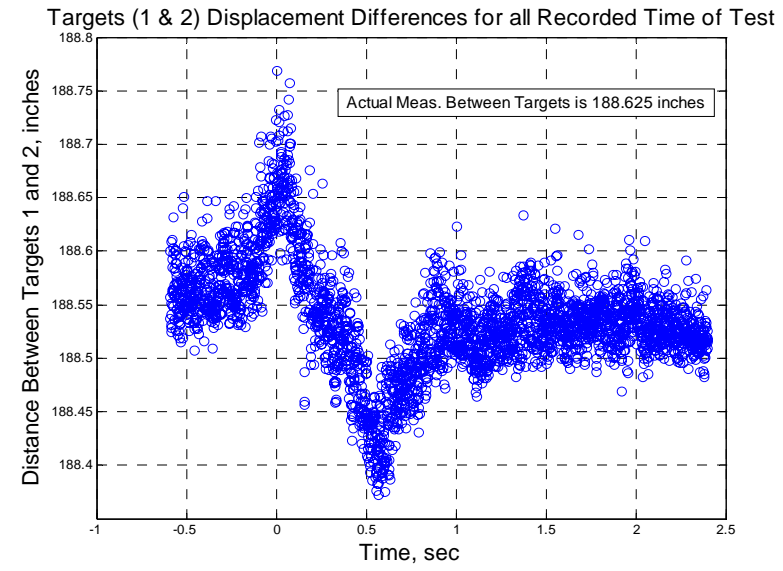

Figure 22: Airbag attenuation vertical-drop model comparison between photogrammetry and scaled measured target separation.

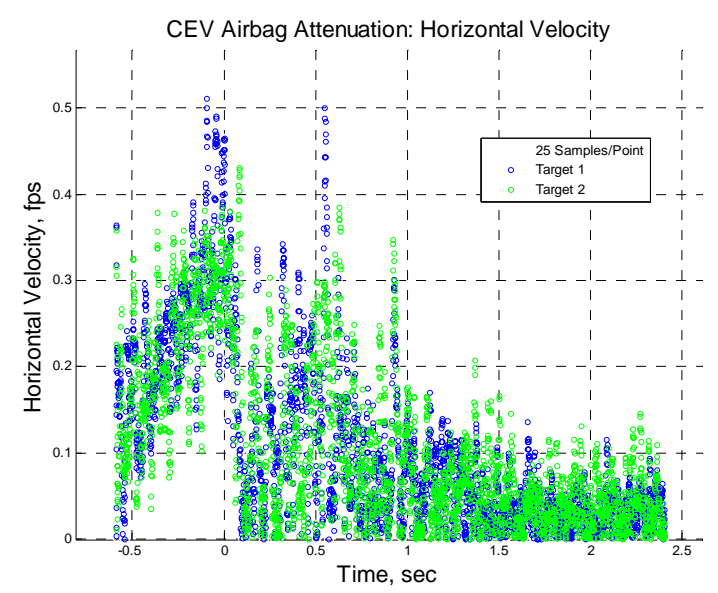

Figure 24: Airbag attenuation vertical-drop model horizontal velocity before and after touchdown at $\mathbf{T}=\mathbf{0}$.

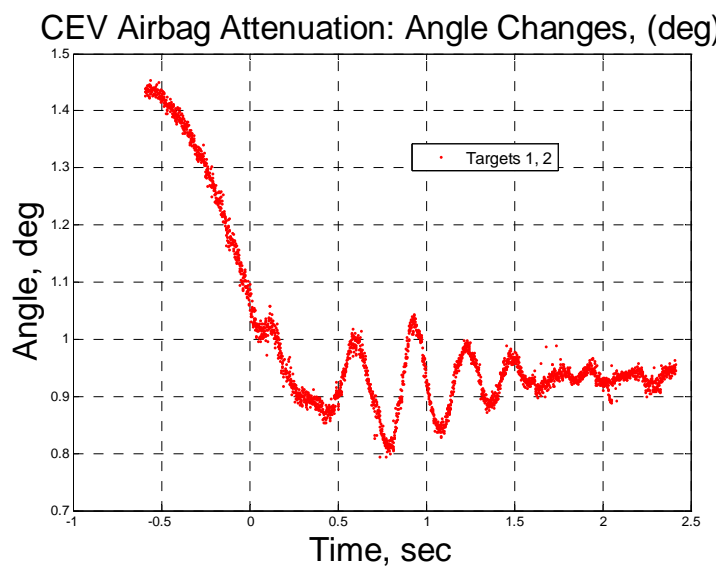

Figure 23: Airbag attenuation vertical-drop model angular changes before and after touchdown at $\mathbf{T}=\mathbf{0}$.

The third test is a pendulum-style drop with an airbag attenuation system attached to the same vehicle as above. The test plans for this model included $40 \mathrm{ft} / \mathrm{s}(12.19 \mathrm{~m} / \mathrm{s})$ horizontal and $25 \mathrm{ft} / \mathrm{s}(7.62 \mathrm{~m} / \mathrm{s})$ vertical, without induced pitch or yaw angles. The starting height for this test was $35 \mathrm{ft}(10.7 \mathrm{~m})$ with average resultant velocity at the time of impact of $47.19 \mathrm{ft} / \mathrm{s}(14.38 \mathrm{~m} / \mathrm{s})$ (horizontal velocity $=39.34 \mathrm{ft} / \mathrm{s}(11.99 \mathrm{~m})$ and vertical velocity $=26.07 \mathrm{ft} / \mathrm{s}(7.95 \mathrm{~m})$ (figures 30 and 31). A heel-first pitch angle present at the time of launch increased at a rate of $1.55^{\circ} / \mathrm{sec}$ as the vehicle descended (figure 28). At $\mathrm{T}=0$ the pitch angle changed $0.16^{\circ}$ in $0.106 \mathrm{sec}$, impacting at a pitch angle of $4.14^{\circ}$. By $\mathrm{T}=0.239 \mathrm{sec}$ the vehicle had compressed its airbags with a nearly zero pitch angle before rebounding back to $4.14^{\circ}$. The scatter in the data for this angle computation of approximately $\pm 0.01^{\circ}$ peak-to-peak is shown in figure 29. Note that the nature of the changes in horizontal velocity shown in figure 30 resembles that shown in figure 18 for the half-scale model with no airbags. In figure 31 the swing cables appear to have released the vehicle a little early for this test, at about $\mathrm{T}=-0.01 \mathrm{sec}$, increasing the vertical velocity by 1 to $1.5 \mathrm{ft} / \mathrm{s}(0.30$ to $0.46 \mathrm{~m} / \mathrm{s})$ at impact. The trajectory for target 1 comes in higher than target 2 because of the $4.14^{\circ}$ heel-in pitch angle of the vehicle. The velocity of target 1 increases as the front (toe-in) side of the vehicle rotates about target 2 and the back half of the vehicle as the rear airbags blow. After target 1 reaches a maximum vertical velocity of $29.3 \mathrm{ft} / \mathrm{s}$ (8.93 $\mathrm{m} / \mathrm{s}$ ) the front half of the vehicle impacts the ground, blowing the front bags and reaching zero vertical velocity in 
approximately $0.1 \mathrm{sec}$ before rapidly increasing back to $12.5 \mathrm{ft} / \mathrm{s}(3.8 \mathrm{~m} / \mathrm{s})$ in less than 60 milliseconds. After that the vehicle violently shutters from one side to the other, as it continues in the horizontal direction at speeds greater than $25 \mathrm{ft} / \mathrm{s}(7.6 \mathrm{~m} / \mathrm{s})$, bouncing its way to a stop.
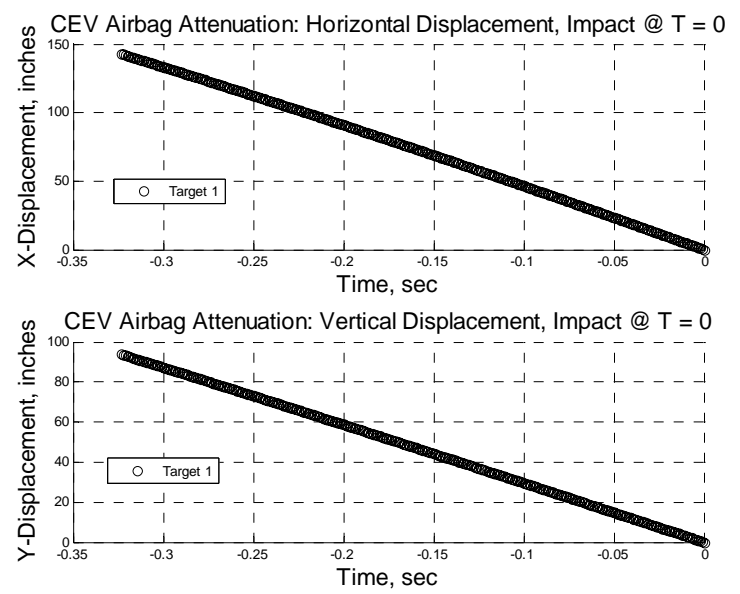

Figure 26: Airbag attenuation swing-drop model horizontal $(\mathrm{X})$ and vertical $(\mathrm{Y})$ displacement, up to touchdown at $\mathbf{T}=\mathbf{0}$.

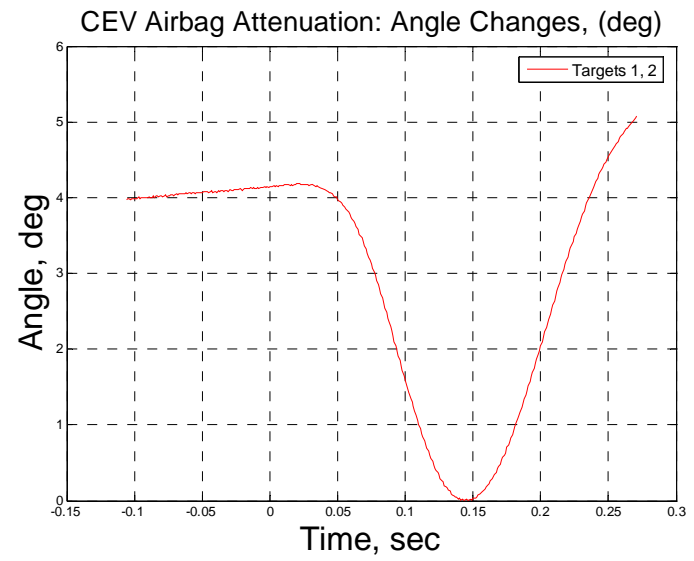

Figure 28: Airbag attenuation swing-drop model angular pitch changes before and after touchdown at $\mathbf{T}=\mathbf{0}$.

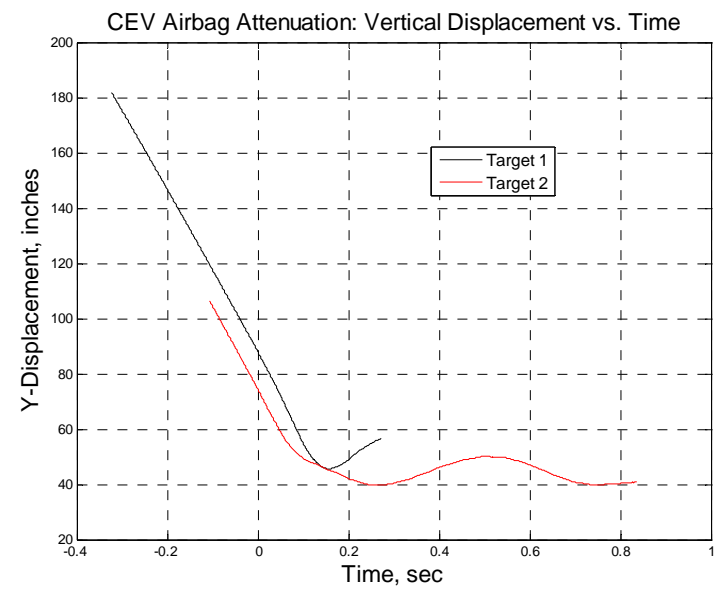

Figure 27: Airbag attenuation swing-drop model, vertical displacement, before and after touchdown at $\mathbf{T}=\mathbf{0}$.

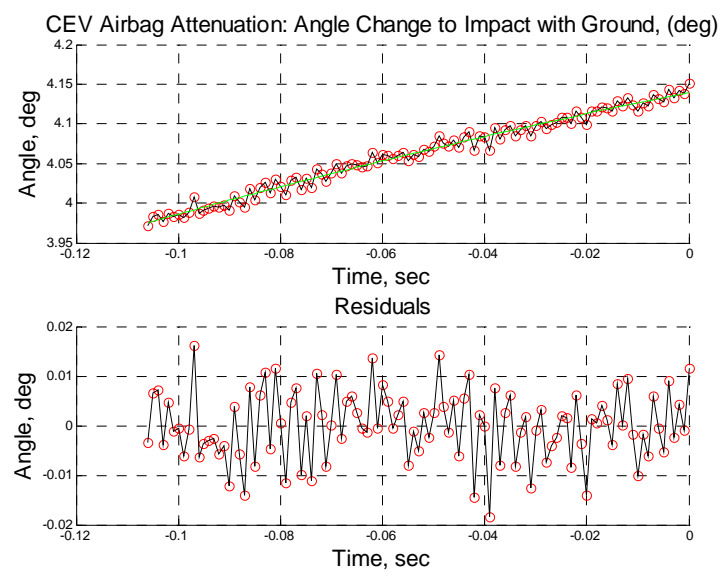

Figure 29: Airbag attenuation vertical-drop model pitch angle changes for last 0.1 (sec) before touchdown at $\mathbf{T}=\mathbf{0}$. 


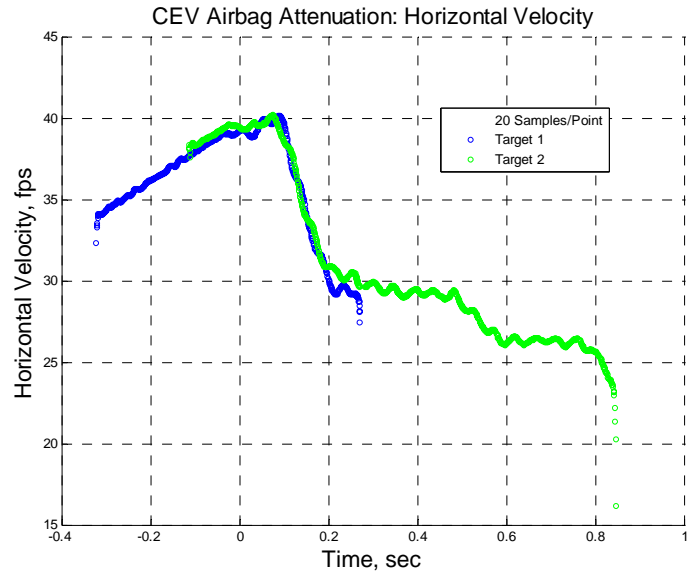

Figure 30: Airbag attenuation swing-drop model horizontal velocity component, before and after touchdown at $\mathbf{T}=\mathbf{0}$.

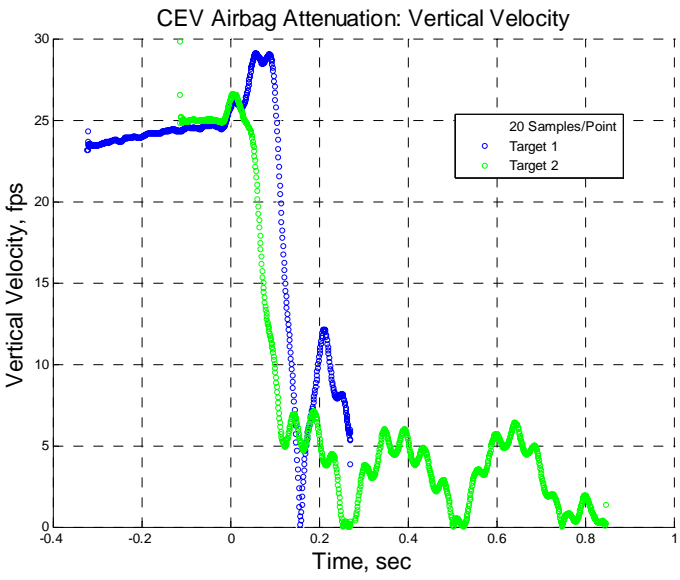

Figure 31: Airbag attenuation swing-drop model vertical velocity component, before and after touchdown at $\mathbf{T}=\mathbf{0}$.

\section{SUMMARY}

Photogrammetric measurements have been used to evaluate the effectiveness of airbags as a landing impact attenuation system. Tests have been conducted on drop models representative of an Orion CEV capsule at the NASA Langley LandIR facility. High-speed (1000 frames per second) video cameras were used to record the drop and impact events. Single camera, single view photogrammetric analyses of the high-speed video sequences produced time-dependent drop model trajectory and impact data for analytical model development and validation. The bias errors associated with the measurement are estimated to be $0.5 \%$ for displacement and velocity and $0.06^{\circ}$ for angles. The 2-sigma precisions of displacement, velocity, and angle measurements were determined to be 0.04 inch, $0.04 \mathrm{fps}$, and $0.006^{\circ}$ respectively.

Studies on airbag CEV land-landing attenuation systems will continue at Langley and elsewhere even as negotiations are being made for landing Orion on water, at least for the current design cycle. By design, landlandings are much cheaper in way of life-cycle costs if the systems can be re-used. Land-landing contingency studies will continue for the near future as a backup to a water-landing.

\section{ACKNOWLEDGEMENTS}

Special thanks are extended to all individuals who have contributed to the CEV photogrammetric efforts at the LandIR Gantry Facility. These individuals include but are not limited to Richard Boitnott, Robin Hardy, and Karen Lyle with the Structural Dynamics Branch, Barry Bryant with the CEV Project Implementation Office, Paul Bagby and Sandra Gibbs of the Media Services Branch, Yamira Santiago with the Safety-Critical Avionics Systems Branch, and Kristina Chapman with the University of Virginia. 


\section{REFERENCES}

${ }^{1}$ NASA’s Exploration Systems Architecture Study, NASA TM-2005-214062, November, 2005.

${ }^{2}$ NASA, Lyndon B. Johnson Space Center, Constellation Program: America's Spacecraft for a New Generation of Explorers - The Orion Crew Exploration Vehicle. FS-2006-08-022-JSC, Houston, TX.

${ }^{3}$ O’Bryan, T. C., and Hewes, D. E., “Operational Features of the Langley Lunar Landing Research Facility”, NASA TN D-3828, February, 1967.

${ }^{4}$ Michelle Cooper, Robert Sinclair, John Sanders, and Jacapo Frigerio, "Design and Testing of an Airbag Landing Attenuator System for a Generic Crew return Vehicle”, 18th AIAA Aerodynamic Decelerator Systems Technology Conference and Seminar, AIAA 2005-1616, 23-26 May 2005, Munich, Germany.

${ }^{5}$ Burner, A. W. and Liu, Tianshu, "Videogrammetric Model Deformation Measurement Technique”, Journal of Aircraft, vol. 38, No. 4, July-August, 2001, pp. 745-754. 